\title{
How to Prevent Injuries for Falling Elders
}

\author{
Shuh Jing Ying* \\ University of South Florida, Tampa, Florida, USA \\ *Corresponding author: Shuh Jing Ying, University of South Florida, Tampa, Florida, USA
}

\section{ARTICLE INFO}

Received: 㓞 July 14, 2021

Published: 幽 July 21, 2021

Citation: Shuh Jing Ying. How to Prevent Injuries for Falling Elders. Biomed J Sci \& Tech Res 37(2)-2021. BJSTR. MS.ID.005988.

\begin{abstract}
We feel that the elder population is increasing everywhere and falling is a serious problem to elders. We ought to find a right solution to help. We first searched the literatures but did not find any paper to solve the problem. Many authors worked how to prevent falling, many companies worked the device to get help after falling. So we are the only one working on preventing injuries for the falling elders. We proposed four devices to protect head, body, knees and hip. Details are given in this report.
\end{abstract}

\section{Introduction}

According to the information revealed on newspapers which is based on the worldwide census of 2016, the total population of whole world is 7.6 billion. Elder population with age greater than 65 is increasing everywhere in all countries. Now it is more than $9 \%$ of the total population. That means 684 million people are in this category. According to ALM Media [1] published in 2015, one out of every three elders will experience of fall. The result of fall usually will lead to injury, very often will have broken bones. Many papers are found in the area of falling elders but all in the subject of detecting falling or preventing falling. Let me mention a few below. T Huang [2] published a paper entitled "Managing fear of falling: Taiwanese elders' perspective". His scheme is in psychological approach, to prevent elders from falling is from the framework of managing fear of falling. Y Zhou, et al. [3] Published a paper in 2020. The title of their paper is "A mixed methods systematic review of informal caregivers' experiences of fall risk among communitydwelling elders with dementia." From the title it is easy to point out this paper is not for general elders, it is for dementia elders. And because the movements of dementia elders are often in the hands of caregivers, so the methods for prevention of falling is also aimed toward the caregivers. Therefore, this paper is totally different from our paper. Many companies devoted their efforts to save elder's life by using a push bottom devices for emergency calls maybe mentioned here for it is certainly related to this paper, Life Saver LLC and Great Call Co. etc.

\section{Our Approach}

Falling is a general term, it can be in many different ways. Falling from the top of roof of a residential building, falling from a top of a ladder, or falling while running can have many different consequences. The proper way to protect these falls can be very different. Here we must state carefully what kind of falling we try to protect. An elder walking at speed not more than $1 \mathrm{mph}$, he is tripped by somethings on the ground or missed the step on the floor, the falling is taking place in a home or around a home. To make it clear let me describe a few examples below. A person walking in his garage fell because tripped by an electric cable on the ground. An elder rushed to answer a phone call fell because of missing a step on the floor. A person fell when he miss judged the height of curb on the roadside. Just to add one more case elder person could fall because slipped on ice on the ground. These falls we are considering in this paper. They are not very serious but serious enough to cause injuries and may reach to broken bones. Because the falls we try to protect are for one's daily life, so devices we are going to use must be available, not expensive and not heavy. The first part of an elder to be protected is the head. Many different hats are considered, hard hat for construction, hard hat for firefighters, helmet for motorcycle riders and helmet for bike riders.

Finally, we choose helmet for bike riders, since it is light and inexpensive and elders can ware it with no interference to their life. To be specific a picture is shown below; (Figure 1) The second 
part of the falling elders is the body. The most common injury to the body is the back pain. It usually takes a few month to complete recovery. To protect our body we must ware something. Here we must consider the temperature, especially in Florida, additional suit can increase the elders' temperature. After a long consideration we feel the vest for boaters may be the right choice. To make it clear a picture is shown below (Figure 2). The next part of the body to be protected is the knees. Serious injury often happened is the broken bones in the knees. Certainly the best treatment is the surgery on the knee. It usually takes a few months to recovery. If you do not have good surgery you may have crippled legs for the rest of your life. So, this is a serious consequence caused by falling. To protect your knees we think the knee sleeves may be the solution. A picture is shown below for your reference (Figure 3). Hip damage often taken place when fell backward. Some serious cases could have bone broken. To protect such injury we think a piece of soft rubber will work. The size of the rubber will be different for different people. The shape of the rubber could be ellipse with the long axis equal to width of person's hip and the short axis equal to the person's body length from waist to the bottom of hip. The thickness of the rubber is to be $1 \mathrm{~cm}$. Let the piece of rubber be attached in the back side of the pants, so hip will be protected when falls. We feel that the four protection devices described above are enough for the falling elders. Damages to the skin of hands, face, body and legs may occur. Because they are not serious injuries so they are not protected.

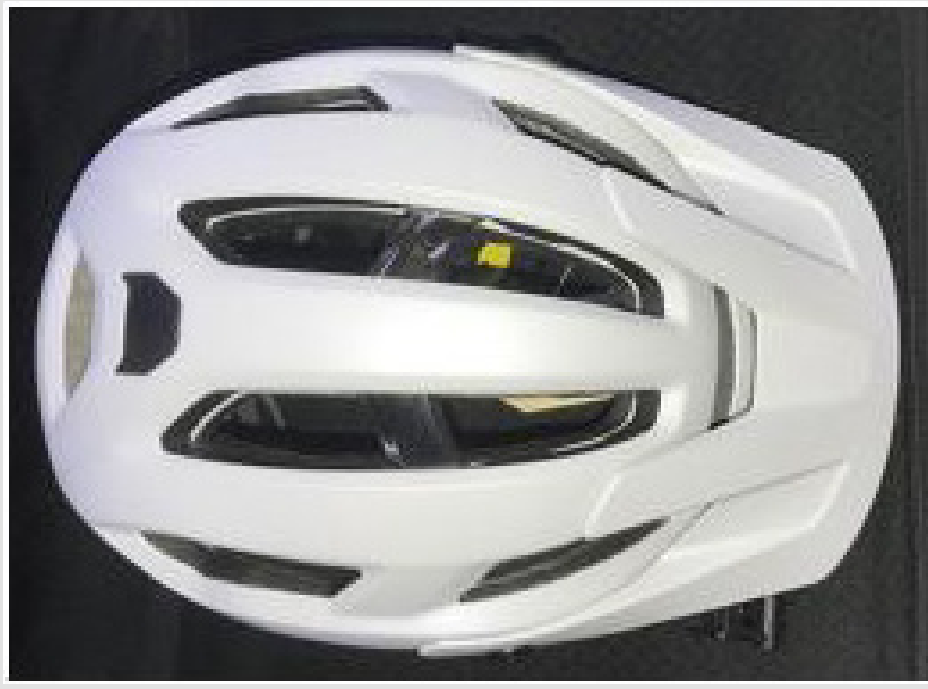

Figure 1: Bike Helmet.

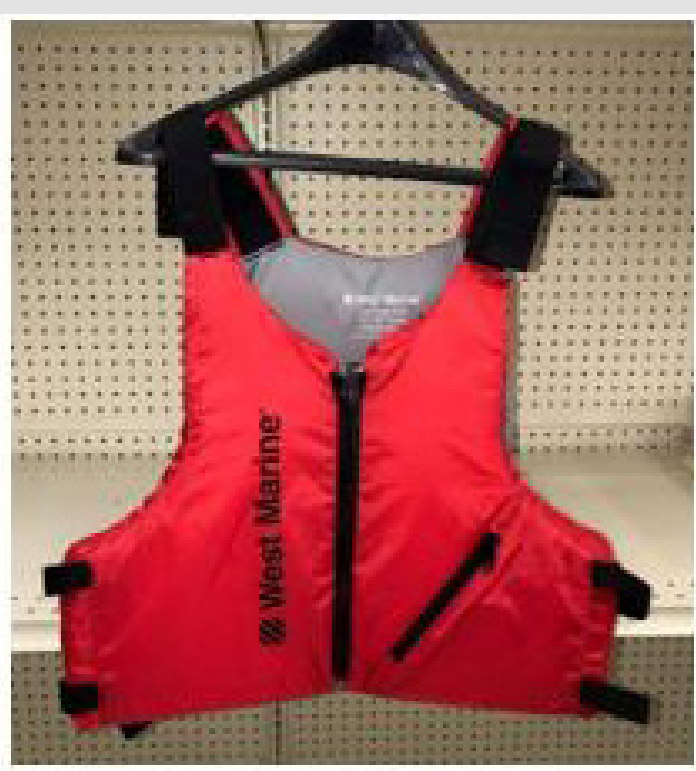

Figure 2: Boater's Vest. 


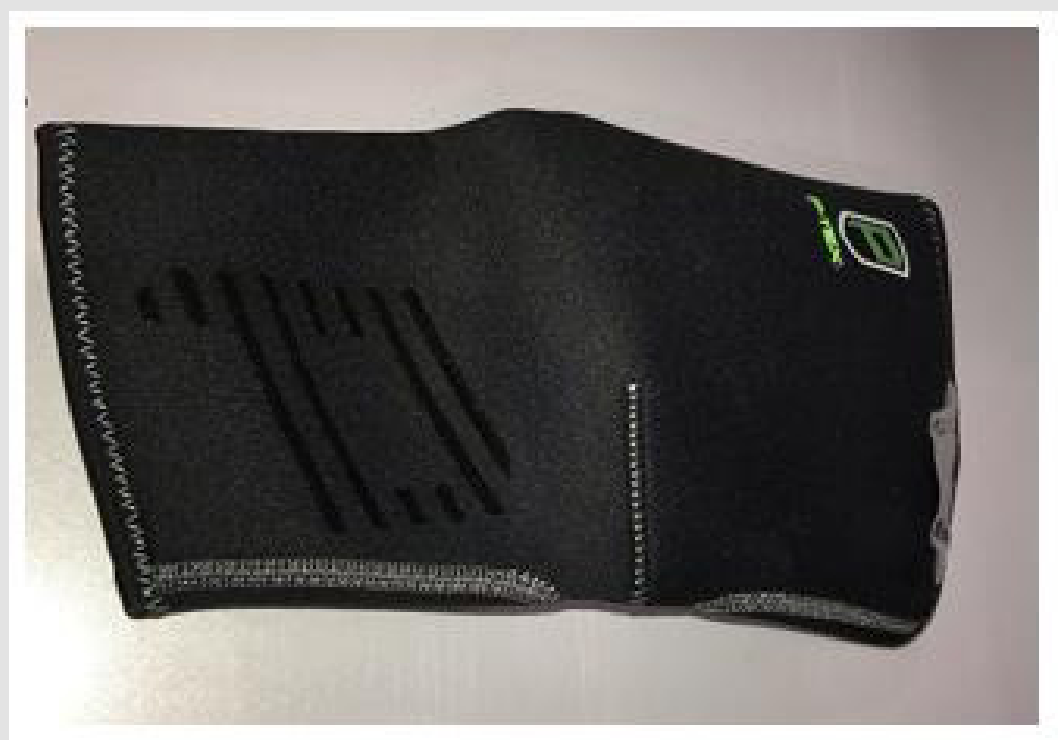

Figure 3: Knee Sleeve.

\section{Conclusion}

We feel to protect falling elders is an urgent problem. But to our surprise no publication is found directly addressing this problem. So we put some effort to figure out what is the best way to prevent the injuries for falling elders. We propose to wear a bike helmet to protect the head, to wear a boater's vest to protect the body, to use knee sleeves to protect his knees and use a piece of soft rubber to protect his hip. In this way serious injuries maybe prevented.

\section{ISSN: 2574-1241}

DOI: $10.26717 /$ BJSTR.2021.37.005988

Shuh Jing Ying. Biomed J Sci \& Tech Res

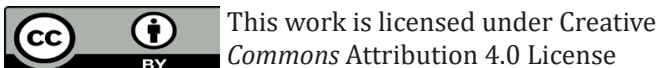

Submission Link: https://biomedres.us/submit-manuscript.php

\section{References}

1. (2015) Elders' Risk of falling is Falling. ALM Media, LLC.

2. Huang TT (2005) Managing Fear of Falling: Taiwanese elders' perspective". International Journal of Nursing Studies 42(7): 743-750.

3. Zhou Y, Strayer AT, Phelan EA, Sadak T, Hooyman NR (2020) A mixed methods systematic review of informal caregivers' experiences of fall risk among community-dwelling elders with dementia". Health and Social Care in the Community 29(4):1126-1144.

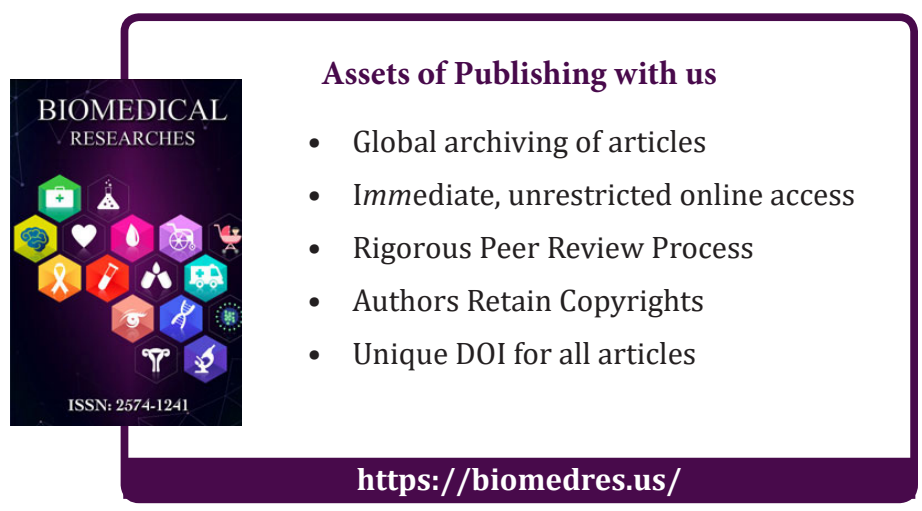

